\title{
8. STRUCTURAL ANALYSIS OF SELECTED LEG 59 CORES, DEEP SEA DRILLING PROJECT
}

\author{
M. Friedman and M. A. White, Center for Tectonophysics, Texas A\&M University, College Station, Texas
}

\section{INTRODUCTION}

Fifteen lengths of Leg 59 cores (primarily from Hole 451 as well as from Holes $447 \mathrm{~A}$ and $448 \mathrm{~A}$ ) exhibiting macroscopic faults were selected by Dr. R. B. Scott (Co-Chief Scientist, Leg 59) to help us initiate this petrofabric analysis (Fig. 1). We proposed to (1) determine what dynamically useful deformation features might be associated with the faults, and (2) infer from these features as much as possible about the physical environment of the deformation (effective pressure, differential stress, temperature, and strain rate), the orientation and relatively magnitudes of the principal stresses at the time of deformation, and the degree of induration of the rocks at the time of deformation. The cores, mainly from Hole 451, are listed in Table 1; they had been slabbed on board ship with respect to the trace of bedding so that each cut surface contains the true bedding dip-direction. In general, the cores from Hole 451 are largely calcareous, lithic and vitric, brecciated tuffs, whereas those from Holes $447 \mathrm{~A}$ and $448 \mathrm{~A}$ are basalts or basalt breccias.

\section{MACROSCOPIC OBSERVATIONS}

At Hole 451 the beds dip from $20^{\circ}$ to $65^{\circ}$ and average $27^{\circ}$ (Table 1, Fig. 2) throughout the sub-bottom interval 128.5 to 898 meters. The steeper dips occur along faults where the bedding is rotated rigidly (Figs. 3 and 4 ). We found 26 small, mainly normal faults in the cores between 385 and 727 meters sub-bottom. All exhibit narrow shear zones with minimum apparent displacements that range from 0 to $42 \mathrm{~mm}$ and average $9 \mathrm{~mm}$; they intersect the beds at angles from $40^{\circ}$ to $90^{\circ}$ (average $74^{\circ}$ ) and are inclined to the vertical core axis at angles from $0^{\circ}$ to $30^{\circ}$ (average $21^{\circ}$ ). In all places where the angle of intersection of the beds and faults is not $90^{\circ}$, the apparent dip of the fault is in the same direction as the true dip direction of the beds. The narrowness of the fault zones and their high apparent dips on the slabbed core surfaces suggest that the strike of the faults and that of the beds are nearly coincident. Faulting is the main deformation mechanism that extends the beds in the bedding dip direction. The orientation of and sense of shear along the faults indicate that the greatest principal compressive stress was vertical and probably equal to the overburden pressure during faulting. Too few unequivocal faults occur in the small number of cores from Holes $447 \mathrm{~A}$ and $448 \mathrm{~A}$ to permit any statements involving deformation at these sites (see Note to Table 1).

\section{MICROSCOPIC DESCRIPTION}

Thin-section observations (Hole 451 cores only) were made to establish criteria that would distinguish be-

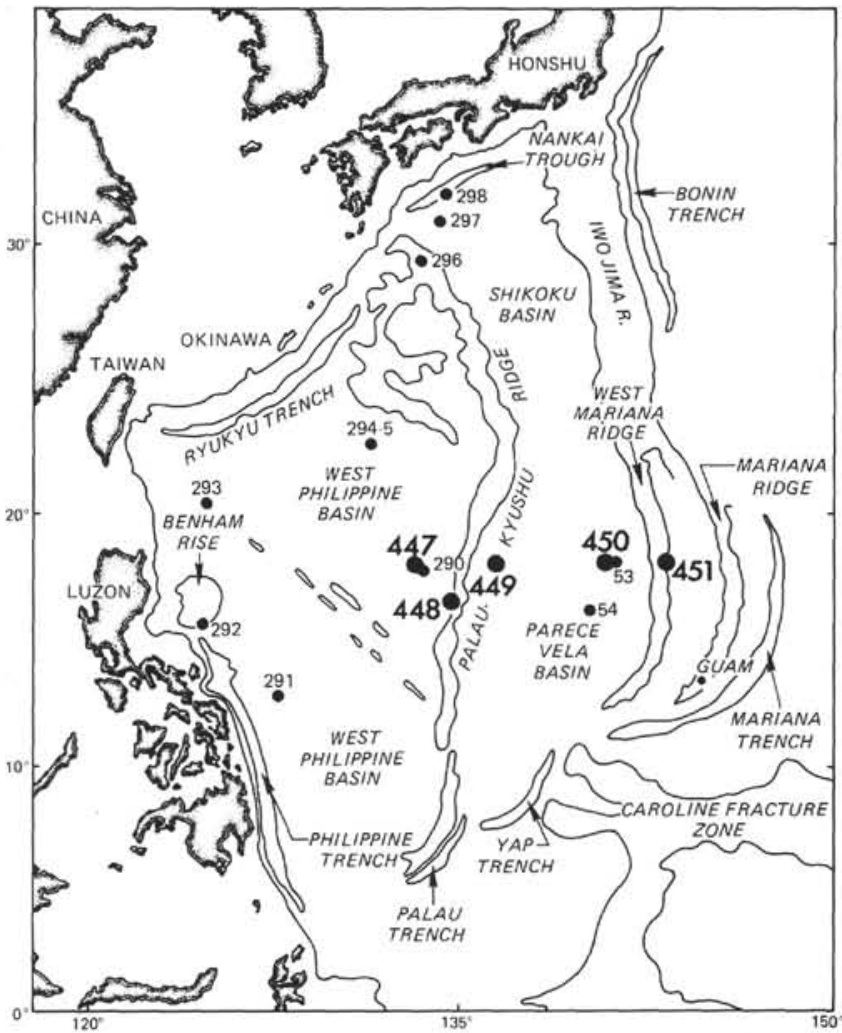

Figure 1. Location map showing positions of Leg 59 sites and some Leg 31 and Leg 6 sites.

tween penecontemporaneous (soft-sediment) and later tectonic deformations. The former deformations are associated with the total depositional and early burial environment; the latter, in principle, can be indicative of the entire structural history of the rocks. We hold that ultimate strength and brittle behavior are directly proportional to the degree of induration, especially since the maximum effective pressures and rock temperatures for these rocks are low.

Criteria in the cores that suggest that some induration took place prior to deformation are as follows:

1) Beds exhibit extension fractures with sharp-edged surfaces (Figures 3 and 4 ), a characteristic that points to brittle behavior.

2) Fragments of bedding are rigidly rotated almost $90^{\circ}$ without further breaking (Figure 4A), which requires a certain strength.

3) Microfractures occur in individual grains and, although randomly oriented, are somewhat more abundant in the immediate vicinity of faults. Such development would not be expected of liquefaction or other 
Table 1. Description of structures in cores.

\begin{tabular}{|c|c|c|c|c|c|}
\hline $\begin{array}{c}\text { Sample } \\
\text { (interval in m) }\end{array}$ & $\begin{array}{l}\text { Dip of } \\
\text { Beds } \\
\left({ }^{\circ}\right)\end{array}$ & $\begin{array}{l}\angle \text { of Beds to Apparent } \\
\text { Fault Dip, } \theta^{\mathrm{a}} \\
\left({ }^{\circ}\right)\end{array}$ & $\begin{array}{l}\angle \text { of Fault to } \\
\text { Core Axis } \\
\left({ }^{\circ}\right)\end{array}$ & $\begin{array}{l}\text { Fault } \\
\text { Displacement } \\
(\mathrm{mm})\end{array}$ & Comments \\
\hline \multicolumn{6}{|l|}{ Hole 451} \\
\hline $42-1,385-394.5$ & 25 & 90 & 25 & 21 & Fault bifurcates to $\theta=0^{\circ}$ and $\mathrm{D}^{\mathrm{b}}=3 \mathrm{~mm}$ \\
\hline $42-1,385-394.5$ & 65 & 85 & 25 & 21 & $\begin{array}{l}\text { Faults bifurcate to } \theta=5^{\circ}, 30^{\circ}, 40^{\circ}, \text { and } \\
\text { rotate beds. Two other faults }\left(\theta=30^{\circ} \text { and }\right. \\
\left.60^{\circ}\right) \text { do not rotate beds }\end{array}$ \\
\hline $42-2,385-394.5$ & 20 & 90 & 25 & 8 & $\begin{array}{l}\text { Two small faults parallel main one for } \\
\text { which data are given }\end{array}$ \\
\hline $46-2,416.2-423.0$ & 20 & 40 & 30 & - & Three parallel faults occur \\
\hline $60-2,537.0-546.5$ & 20 & 50 & 25 & 8 & Fault helps to rotate adjacent blocks \\
\hline $63-5,565.5-575.0$ & 20 & 65 & 15 & 13 & $\begin{array}{l}\text { Smaller conjugate faults developed that } \\
\text { intersects main fault at } 40^{\circ}\end{array}$ \\
\hline $64-2,575.5-584.5$ & 20 & 80 & 23 & - & $\begin{array}{l}\text { Fault divides into three branches with } \theta= \\
15^{\circ}, 40^{\circ} \text {, and } 60^{\circ}\end{array}$ \\
\hline $68-2,613.0-622.5$ & 20 & 65 & 0 & 42 & $\begin{array}{l}\text { Younger fault with } \theta= \\
70^{\circ} \text { offsets main fault }\end{array}$ \\
\hline $80-1,717.5-727$ & 40 & 80 & 25 & 5 & Single fault \\
\hline \multicolumn{6}{|l|}{ Hole $448 \mathrm{~A}^{\mathrm{c}}$} \\
\hline $37-1,698.5-708.0$ & - & - & - & - & Possible shear zone in basalt breccia \\
\hline $46-1,768-774.5$ & - & - & - & - & Fracture developed in basalt \\
\hline $51-3,801.5-810.5$ & - & - & - & - & Possible shear zone in basalt \\
\hline \multicolumn{6}{|l|}{ Hole $447 A^{c}$} \\
\hline $28-1,217-218$ & - & - & - & - & Undeformed pillow basalt \\
\hline $29-4,230-231$ & - & - & - & - & Undeformed pillow basalt \\
\hline $35-6,282.5-283.7$ & - & - & - & - & Undeformed pillow basalt \\
\hline
\end{tabular}

a Except when $\theta=90^{\circ}$, the dip-direction (bearing) of the fault and that of the bed are the same.

$\mathrm{b} \mathrm{D}=$ fault displacement.

c Statements on deformation cannot be made, given that too few unequivocal faults were found in these samples.

types of water-escape processes normally associated with soft-sediment structures (Lowe, 1975, 1976).

4) A few macrofractures must have propagated through glass fragments and detrital crystalline grains. Again, this would not be expected of soft-sediment deformation.

Secondary minerals as well as voids occur along the natural open fractures (Figure 5A, B). Thus, even though filled with fluids at pressure, the fracture surfaces had sufficient strength to maintain openings from the time of fracturing until the present.

6) Fault zones occur that in places are masked by fine-grained material resembling gouge (Figure 5B). Gouge would not form upon soft-sediment slumping.

7) Highly fractured feldspar porphyroclasts and crushed nannofossils occur in a fragment of vitric tuff (Figure 6). These features require high differential stresses and suggest a high degree of induration at least for that fragment of vitric tuff.

Criteria suggesting that the degree of induration was only slight at the time of deformation are as follows:

1) Sharp-edged extension fracture surfaces are easily indented by unfractured glass fragments (Figure 4B); indention hardness is low.

2) Extreme but local "tectonic" thinning of beds (Figure 4A) occurs along shear zones, and spaces between separated fragments of beds are infilled with tuffaceous material, suggesting soft-sediment flow.

3) In the main, calcareous nannofossils are unbroken and calcite crystals in their walls are untwinned (Figure 5C), which points to small differential stresses.

\section{CONCLUSIONS}

Microscopic evidence for at least some degree of induration of the rocks prior to deformation-coupled with the uniform tilt of the beds, the small displacements along the faults (up to $42 \mathrm{~mm}$ ), and the parallelism of bedding and fault strikes-suggests that the deformation pervades the cored sedimentary pile and reflects the structural framework of the regional geology, a style marked by lateral extension, oriented parallel to the dip of the beds. This view seems more consistent with the facts than does the alternative, that the deformation took place at or near the depositional interface and reflects local topography and dewatering conditions.

\section{REFERENCES}

Lowe, D. R., 1975. Water escape structures in coarse-grained sediments. Sedimentology, 22:157-204. 1976. Subaqueous liquefied and fluidized sediment flows and their deposits. Sedimentology, 23:285-308. 


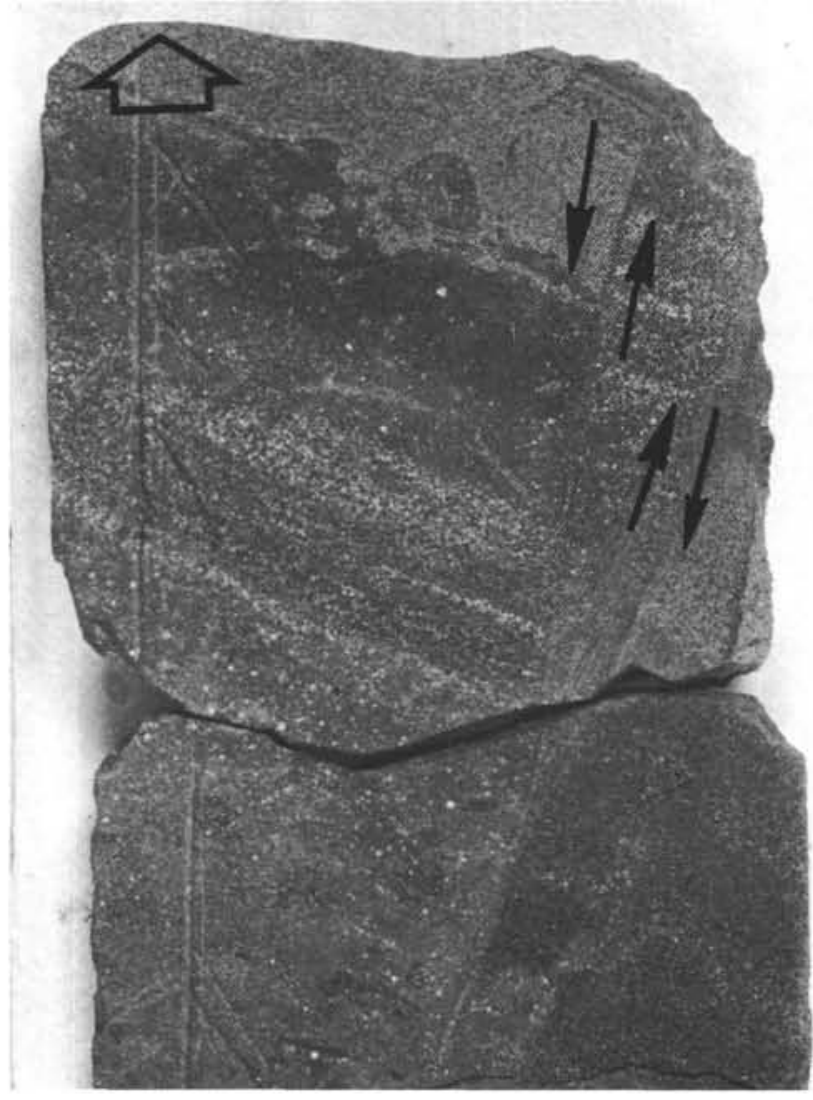

Figure 2. Photograph of a high-angle fault zone developed in carbonate-rich, vitric tuff (Sample 451-42, 335-394.5 m). Fault zone is normal to bedding, which dips $25^{\circ}$ to the right. Outline arrow indicates "up" direction in vertical core. Sense of shear arrows reflect apparent displacements. All cores were slabbed perpendicular to bedding so that the cut surface contains the beddingdip direction. Accordingly, the narrowness of the fault zone and its steep dip indicate that the strike of the fault is essentially parallel to that of the beds. Core diameter is $6.0 \mathrm{~cm}$.

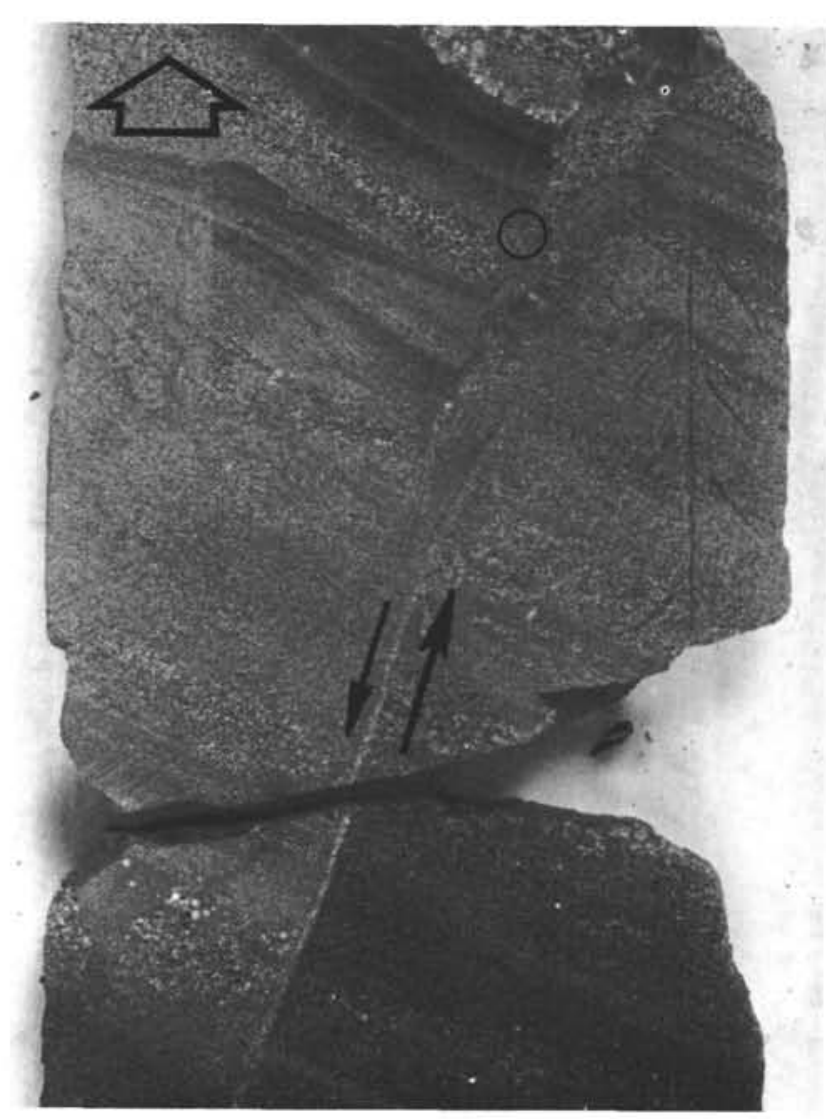

Figure 3. Photograph of a fault zone in carbonate-rich, vitric tuff (Sample 451-42, 385-394.5 m). Outline arrow shows “up" in vertical core. Sense of shear arrows show apparent displacement. Open circle is location of center of thin section shown in Figure 4. Bedding dips $\sim 25^{\circ}$ to right. Note bifurcation and drag of material above and below open circle along fault. Core diameter is $6.0 \mathrm{~cm}$. 

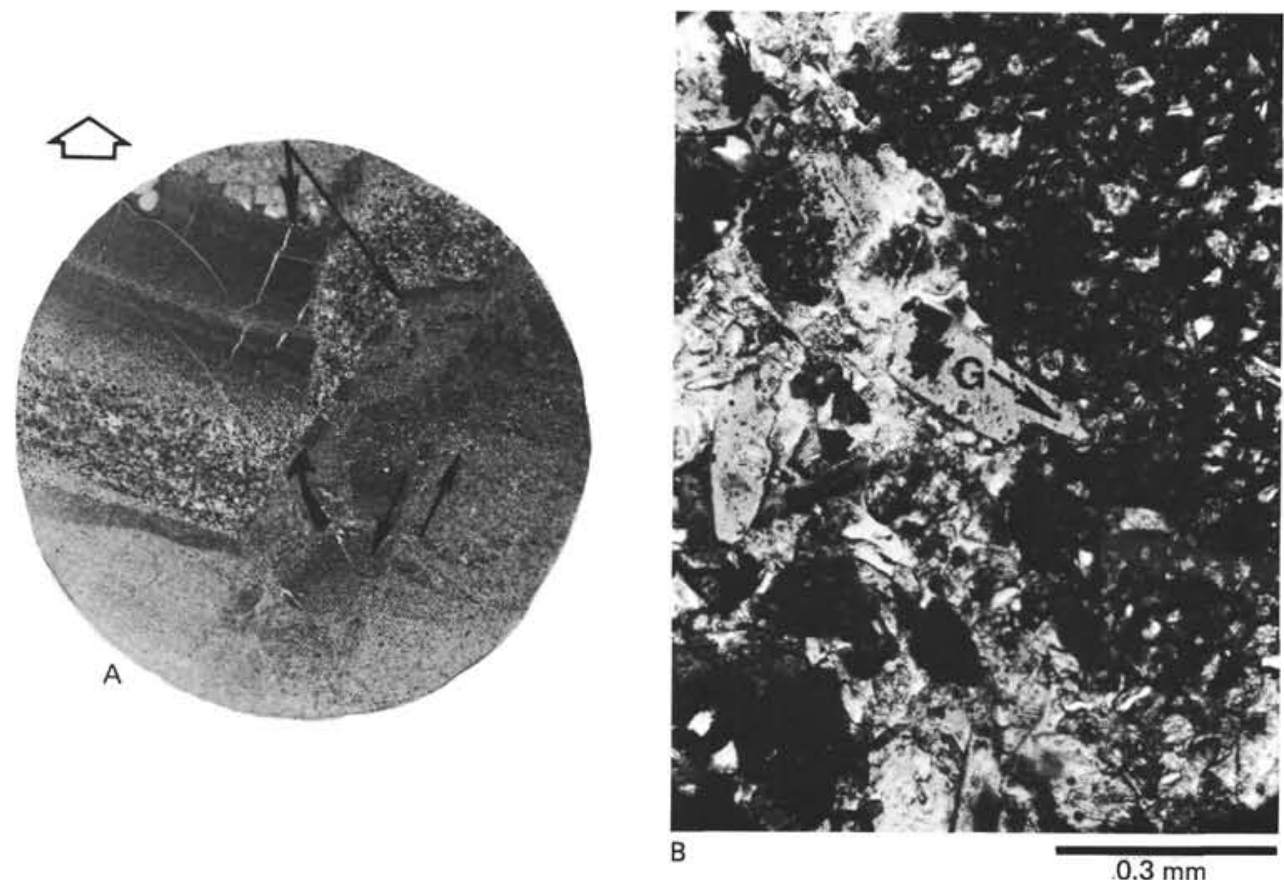

Figure 4. Photomicrographs show details of deformation about open circle in Figure 3 (Sample 451-42, 385-394.5 m): A. View of whole thin section shows extension fractures normal to bedding (short, straight arrows), coarse-grained material thinned markedly at center of field of view, material in down-thrown block fractured, and fragments of bedding separated and rotated nearly $90^{\circ}$ (curved arrow). Outline arrow shows "up" in vertical core. B. Fragment of glass (G) is indented into fractured surface (long, straight arrow in [A], which indicates material was not indurated at time of deformation). Plane polarized light. Scales: 4A circular thin section is $2.5 \mathrm{~cm}$ in diameter; 4B scale line is $0.3 \mathrm{~mm}$. 

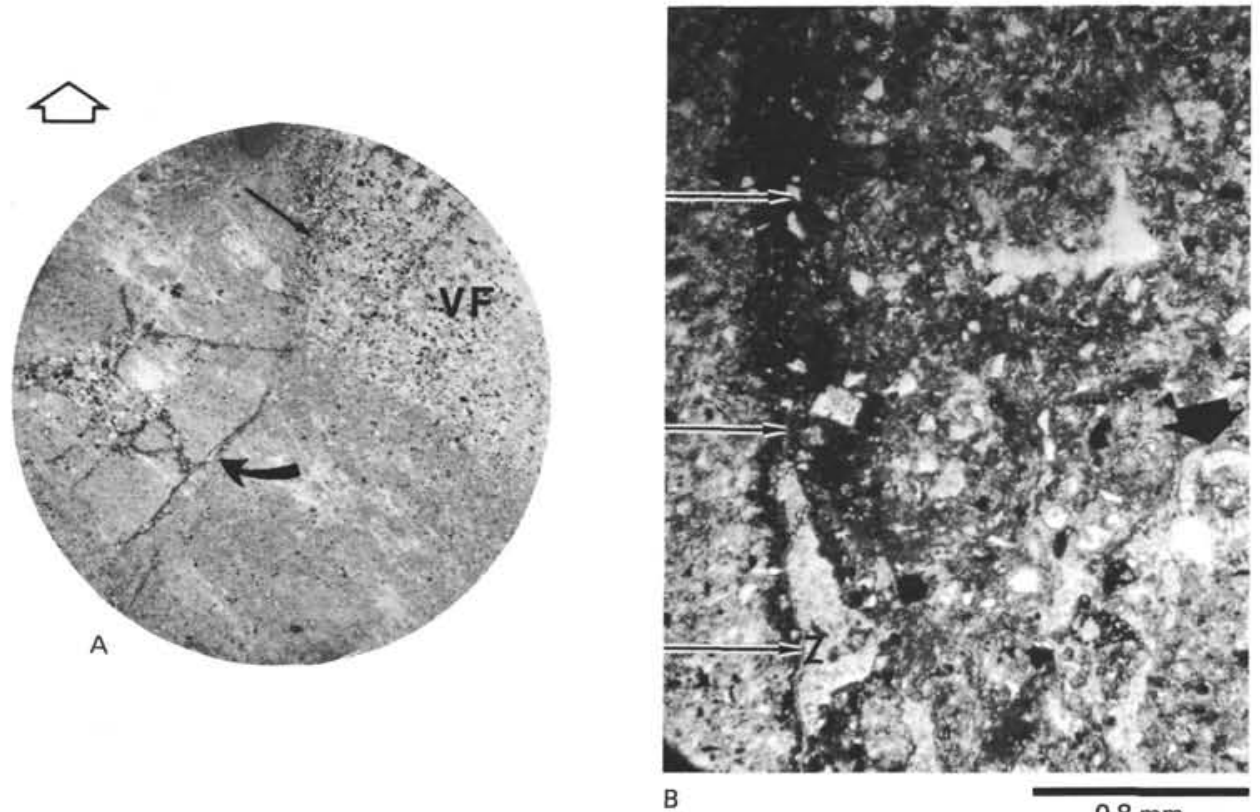

$0.8 \mathrm{~mm}$

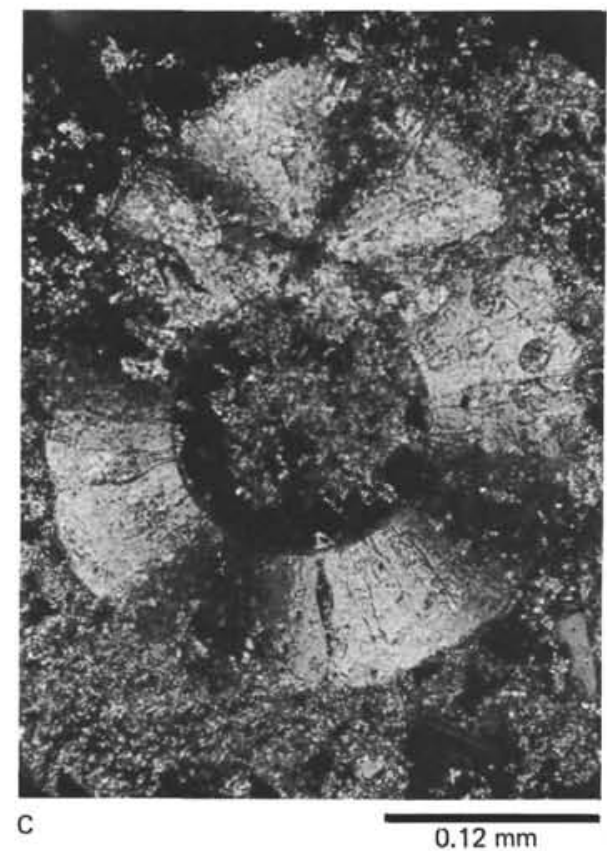

Figure 5. Photomicrographs show details in lithic and vitric breccia (Sample 451-60, 537.0-546.5 m): A. Overview of thin section shows coarser-grained, vitric fragment (VF) and adjacent finer-grained, fractured lithic material. Contact marked by straight arrow is a sheared surface. Outline arrow indicates "up" in vertical core. B. Fracture (arrows) with associated gouge (fine, dark material) and mineral filling ( $\mathrm{z}$ ) at location in 5A marked by curved arrow. Note broken nannofossil (bold arrow) near this fracture. C. Nannofossil in fine-grained material away from fracture is undeformed. Figures $5 \mathrm{~A}$ and $5 \mathrm{~B}$ in plane polarized light; $5 \mathrm{C}$ in crossed polarized light. Scales: $5 \mathrm{~A}$ is $2.5 \mathrm{~cm}$ in diameter; scale lines in 5B and 5C are $0.8 \mathrm{~mm}$ and $0.12 \mathrm{~mm}$, respectively. 

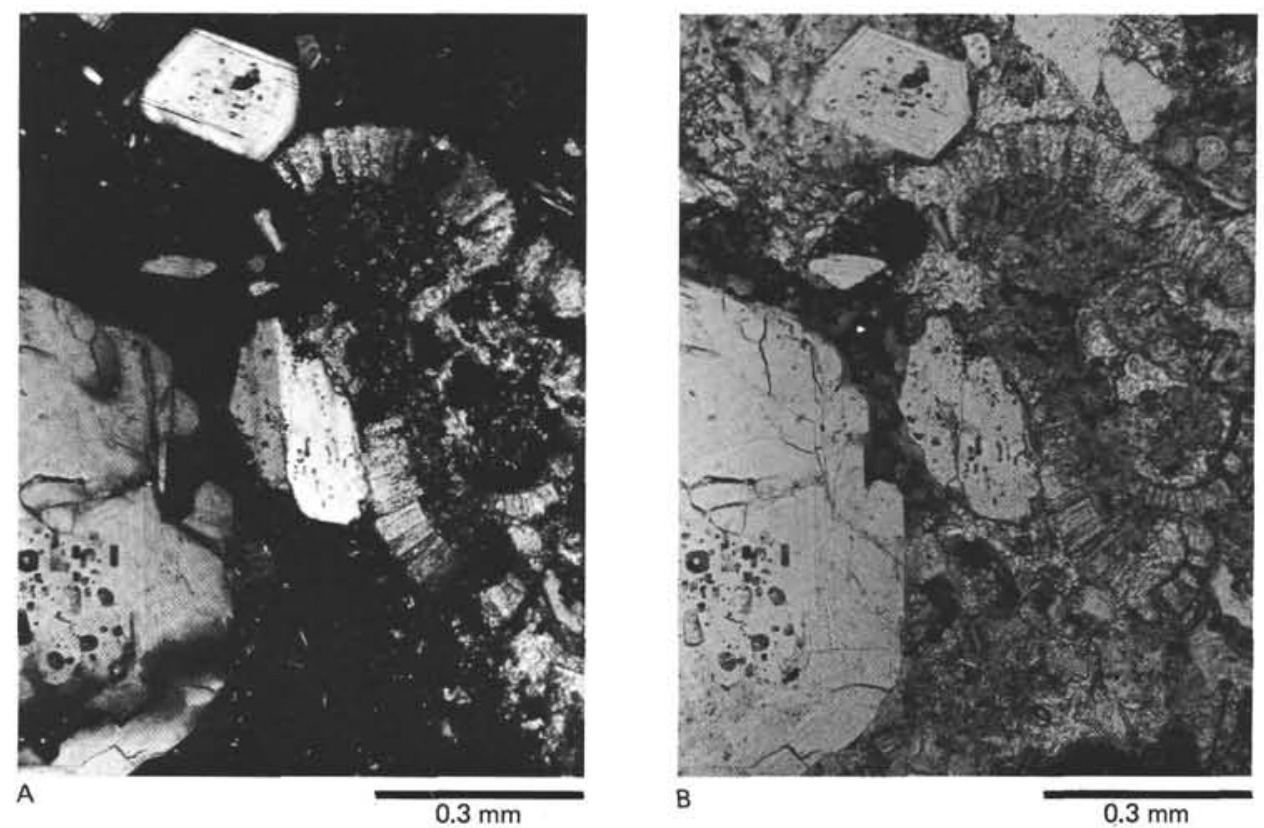

Figure 6. In Sample 451-60, 537.0-546.5 m, fractured feldspar and crushed nannofossil in vitric fragment (VF, see Figure 5A) indicate elevated differential stress levels probably developed in deformation of that fragment prior to its present position. Figure 6A in crossed polarized light; Figure 6B in plane polarized light. Scale line is $0.3 \mathrm{~mm}$. 